\title{
PROCEDURES FOR OPERATING THE NEW ZEALAND STRONG-MOTION ACCELEROGRAPH NETWORK
}

\author{
Richard T. Hefford*, Pamela M Randel*
}

To be presented at the Third South Pacific Regional Conference on Earthquake Engineering, Wellington, May 1983.

\section{SYNOPSIS:}

The procedures for operating the New Zealand strong-motion accelerograph network are described. In order to maintain and operate such a network, a careful and systematic programme needs to be adhered to. Details are given of site selection, preparation for field visits, instrument servicing procedures, types of film and processing and the documentation of information obtained. The latest modifications to the MO2 accelerograph, to encode a radiotransmitted time signal on the film to indicate the relative triggering time, are discussed and the new installations to monitor the response of the base-isolated William Clayton building and South Rangitikei bridge are described.

\section{MAINTENANCE OF NETWORK}

\section{Introduction:}

The strong-motion earthquake recorder network operated by the Physics and Engineering Laboratory, DSIR, is based on the New Zealand built mechanical-optical (MO) accelerograph developed at the Laboratory. Many improvements and modifications have been made to the accelerograph since the installation of the first MOl in 1966. Peak reading accelerographs using a smoked glass disc, also designed and built at PEL, are used to augment the network.

From the point of view of servicing the instruments, New Zealand is divided into five zones (Figure la). Each instrument site is visited every eight months with the exception of the two accelerographs on the Maui A Offshore Platform, which are serviced every four months because of the large ambient vibrations present, and the conditions under which the instruments are operated. This gives approximately thirty working days in which to service all the instruments in a particular zone. Zone 2 (including Hutt Valley and Wellington) has sixty working days allocated for servicing due to the large number of instruments installed.

The maintenance programme is normally the full-time responsibility of two technicians from the Engineering Seismology Section, DSIR, and at times one other member of PEL staff is seconded to assist for the duration of the field visits, normally 7-12 days. The balance of the thirty working days is spent in the preparation of the field visits, overhauling the instruments brought back from the field and in the processing and documentation of information obtained. It is of extreme importance that the servicing programme for a particular zone

*Engineering Seismology Section, Physics and Engineering Laboratory, DSIR, Lower Hutt, New Zealand. is completed before the start date of the next zone. A systematic programme is the only way to achieve the reliability of the accelerograph network, which includes ensuring both that the instruments are operational and data on their location and calibration is complete and accurate. Accelerometer blocks or complete instruments are sometimes replaced and small records may not be digitised for a considerable time after their recovery. Consequently it is often necessary to know which instruments and which accelerometer blocks were installed at a site several years previously, and their calibration characteristics.

\section{Site Selection:}

As most of the installed accelerographs are owned by other agencies such as Ministry of Works, Electricity Division of Ministry of Energy, and State Services Commission and have been provided for specific projects, DSIR is limited in site selection. Over the last couple of years the Road Research Unit of the National Roads Board has been helpful in providing instruments for sites adjacent to bridge structures which have filled gaps in the total network. Instruments installed since the last description of the network in 1979 (1) are marked in the distribution map of Figure 1c. At the end of 1982 the network gave a good coverage of New Zealand, although the recording of nearfield motion in many areas would be reliant on a single instrument. There is only one large localised array which is in the Hutt Valley and Wellington area. At present there is a lack of information on the structural response of the typical 2-3 storeyed commercial buildings that are common throughout New Zealand. Consideration is being given to instrumenting this type of building, probably in the Lower Hutt area initially. Although the number of strong-motion accelerographs has increased over the years, the network is still maintained 


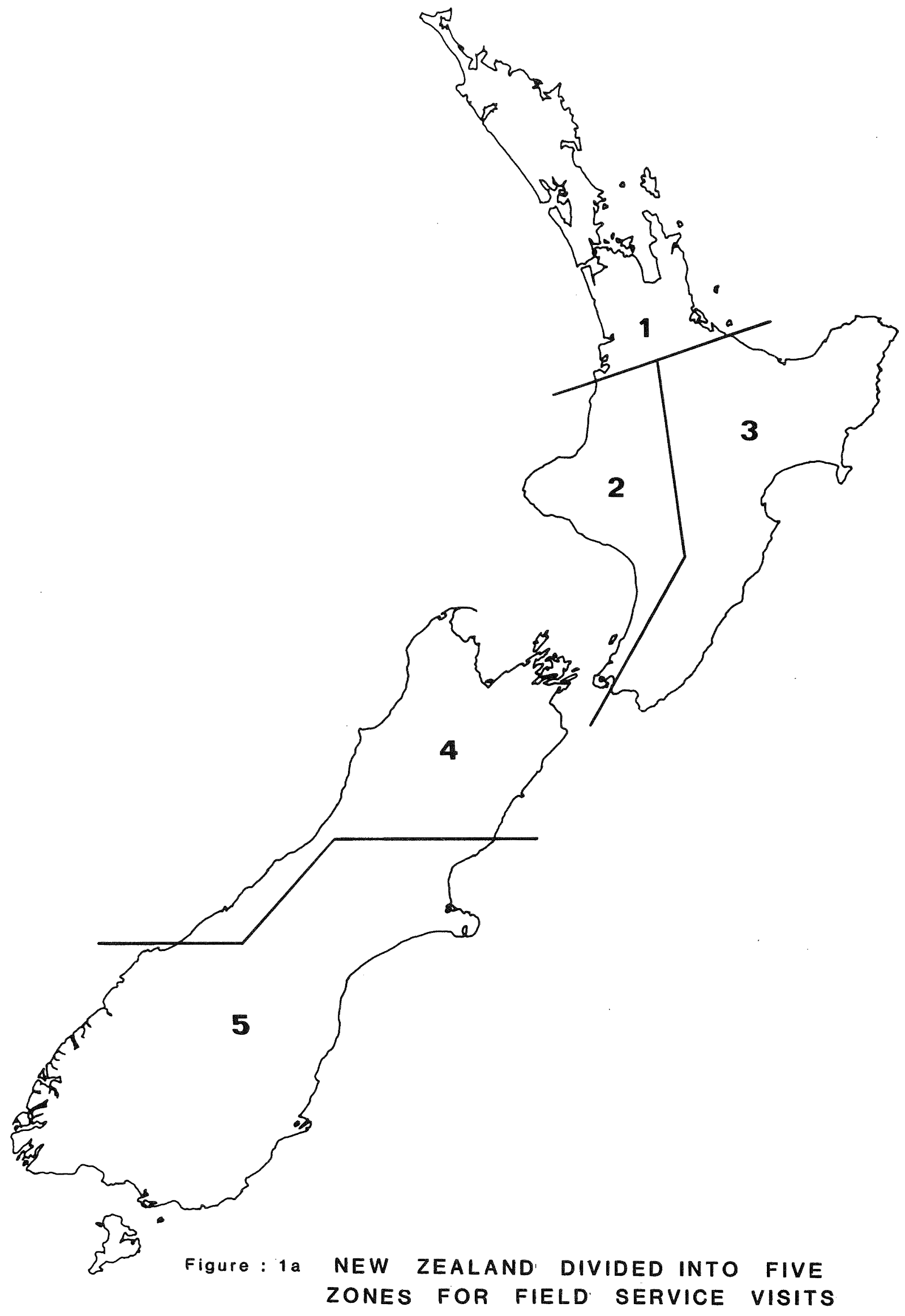




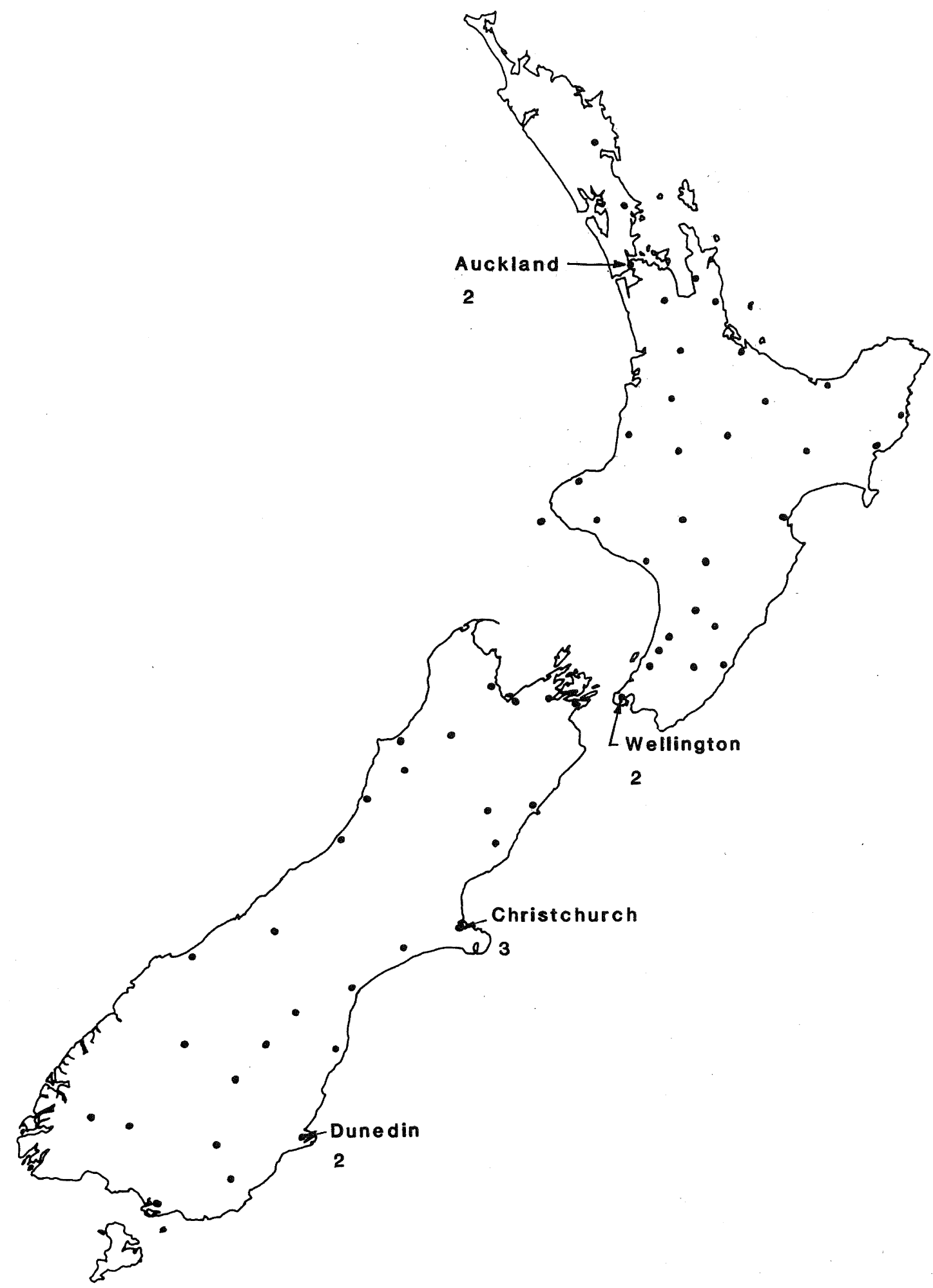

Figure 1b DISTRIBUTION OF S.P. INSTRUMENTS IN THE NEW ZEALAND NETWORK 


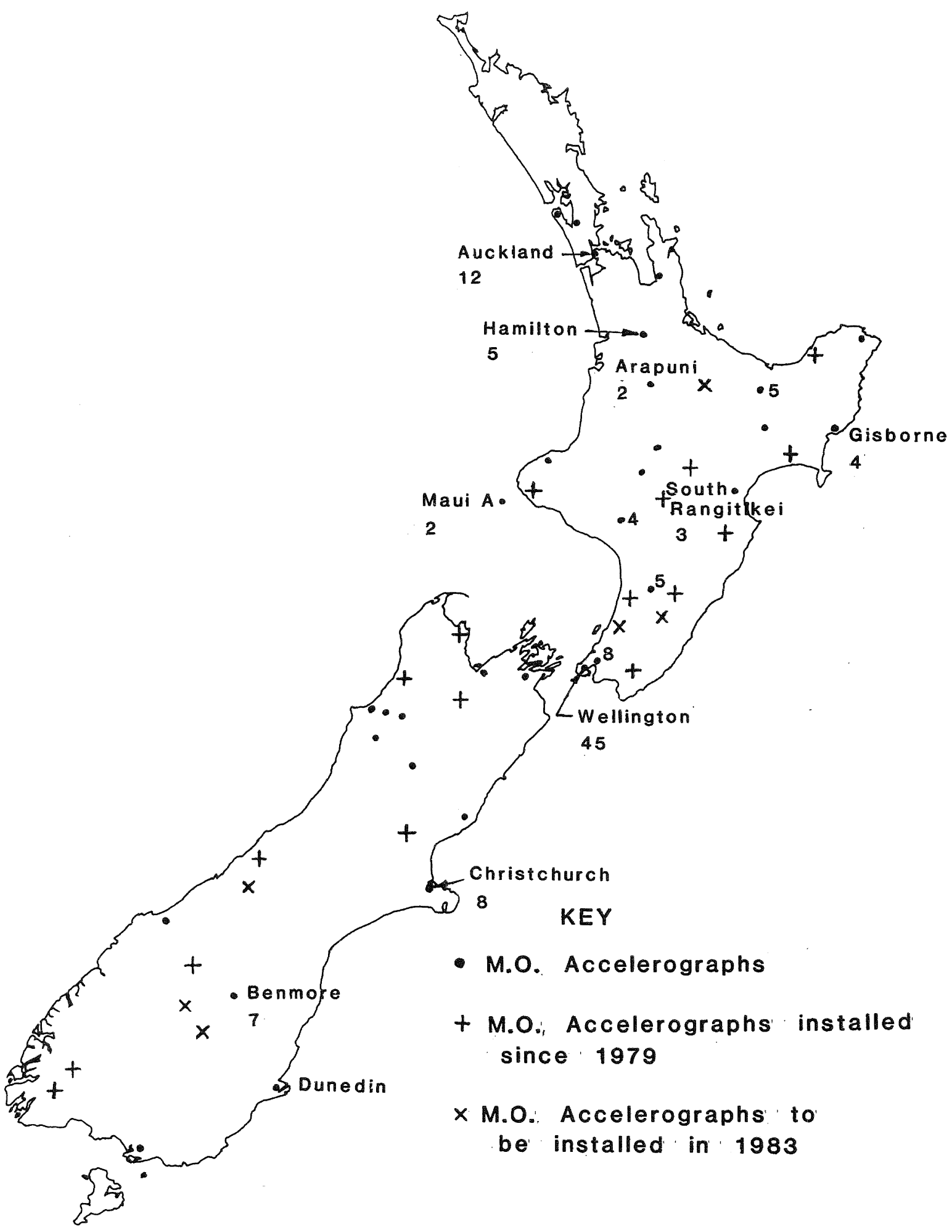

Figure: $1 \mathrm{c}$. DISTRIBUTION OF M.O. ACCELEROGRAPHS IN THE NEW ZEALAND NETWORK 
and supported by the same number of staff, which therefore limits the number of accelerographs which can be serviced by PEL to a total of 225 of all types. This total will be reached about the date of this conference. Installation of three component time-based accelerographs will continue at sites of special interest, with the limit of 225 retained by removing obsolescent MOI and SP accelerographs from adjacent sites.

It is an important factor in site selection to have, where possible, access to the sites outside Wellingon on weekends, as DSIR technicians in the field work during the weekends. Most of the sites in use at present are in telephone exchanges, fire stations, and police stations. These public buildings are more suitable for the installation of accelerographs as privately owned buildings tend to change hands and access is not usually obtainable outside normal working hours. However, many interconnected accelerographs are located in multi-storey office buildings and access is only possible during normal working hours. Other sites include dams. bridges and motorways (1). When accelerographs are first installed or their location is changed, an instrument orientation sheet is prepared (Figure 2).

To give true measurements of ground or building response rather than support vibrations, accelerographs must be firmly mounted, and mountings such as cantilevered steel brackets are no longer acceptable. "Terrier" masonry anchors, together with heavy steel RSJ's or concrete plinths are used for accelerograph mountings. Holes are drilled in the concrete plinths and accelerograph feet are embedded in plaster of paris in the drilled holes. In sites that have high ambient vibrations such as a bridge deck, for example the South Rangitikei Railway Bridge and the Bowen Street overbridge in Wellington, the accelerographs are best triggered from a remote site.

\section{Preparation for Field Visits:}

The first steps in preparing field visits are the routine but necessary tasks of allocating dates, taking into consideration school holidays when accommodation may be difficult to obtain and any staff commitments, arranging a suitable DSIR vehicle, and making ferry bookings for South Island trips. A standard letter of notification (Fig. 3) is sent to property owners so DSIR staff will be expected and less delay experienced in gaining access to security areas. The work schedule sheet (Fig. 4), written up after the last visit to the zone, is consulted to determine the number and type of film cassettes and batteries to be prepared and any additional accelerographs, equipment or spare parts required. Major repairs to accelerographs are normally carried out in the laboratory, and a programme of returning at least one accelerograph per field visit for repair, overhaul and updating is planned.
The MOl accelerograph uses $7.5 \mathrm{~m}$ of $35 \mathrm{~mm}$ unperforated film, type Kodak RAR 2495, and cassettes are wound with the emulsion side in, whereas the MO2 accelerograph uses identical film but different cassettes with the emulsion side out. The MO2A uses $7.5 \mathrm{~m}$ of $35 \mathrm{~mm}$ unperforated film, type Ilford $200 \mathrm{~A}$ surveillance film, or Kodak PLUS-X PAN film. Smoked glass slides are prepared for the scratch-plate accelerographs.

As the MO type accelerograph consumes practically no power in the standby mode, and little when triggered, experience has shown that dry cell batteries are most suited for this operation. This is an advantage over most overseas manufactured accelerographs which have greater power consumption, especially in the standby mode, and usually require rechargeable batteries on float charge from mains power. In order to reduce costs, and the weight of batteries carried, battery type and capacity are tailored to suit site conditions. Batteries with high capacity and long shelf life. Eveready No. 6 cells, are used in extreme environments. Eveready No. 731 Lantern batteries are used in average conditions and Eveready No. 609 are used mainly in multi-storey buildings where conditions are favourable. All battery connections are soldered in the Laboratory and batteries are given a high discharge voltage test, appropriate for the battery type, before they are packed for field use. At many sites batteries are changed only every second trip, at about 16 month intervals, providing they pass a further high discharge test, using laboratory designed test equipment.

Additional film cassettes, scratch plate slides and an additional instrument are carried to cover the event of an earthquake occurring while the network maintenance technicians are away from the laboratory. For example, at the end of last year staff were diverted to Wanganui during a field service visit to zone 3 (East Coast North Island). They carried with them a spare MO2 accelerograph and sufficient film and SP slides to enable installation of a temporary MO2 accelerograph in the Wanganui Police station, and to service the SP accelerographs in the Wanganui Post Office and the MO2 accelerographs at Atene and Palmerston North. An additional MO2 was taken up by another staff member from Wellington and installed at Ohakea.

\section{Instrument Servicing Procedures:}

The stationwagon used for the field visit is systematically loaded the day before the field visit commences, working from a check list. The order in which the accelerographs are to be serviced and any additional repairs necessary are noted on the work schedule sheet. A copy of this sheet is retained in the Laboratory in case field staff need to be contacted. A field book for each site is carried with information on site location and the person to contact to gain site access. In some cases where sites are not manned, keys to the building are attached to the appropriate field 


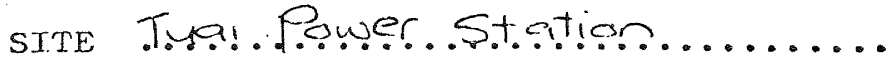

instrument . M. . . ................ survey MWD Power Design

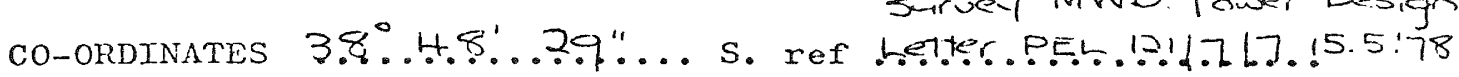
$17.7 \% . .99^{\prime} .0 .8 . . \cdots \mathrm{E}$.

ORIENTATION - true ...3.9.?.... from . .24. 4.166 to .......

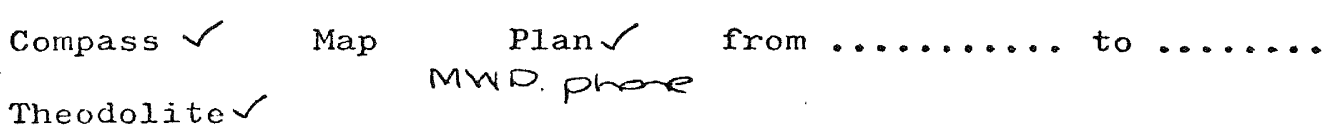

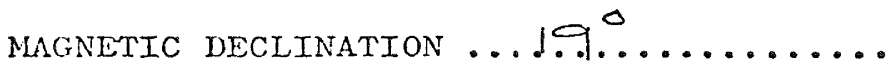
BEARING - street $\ldots \ldots \ldots \ldots \ldots$ mag $\ldots \ldots \ldots \ldots$ true $\ldots \ldots$ refs

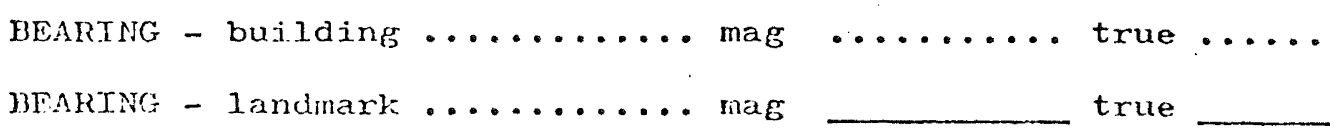
ANCEE - building to landmark - subtract check $\operatorname{refis} \quad \ldots \ldots \ldots \ldots \ldots \ldots \ldots \ldots$

ANGLE - buildine axis to instrunent axis ............. $r e f ' s \quad \ldots \ldots \ldots \ldots \ldots \ldots \ldots \ldots$

INSTRUMENT AXIS mag $\frac{283^{\circ}}{\text { magnetic }}$ true B...?.

Sketch

Refs
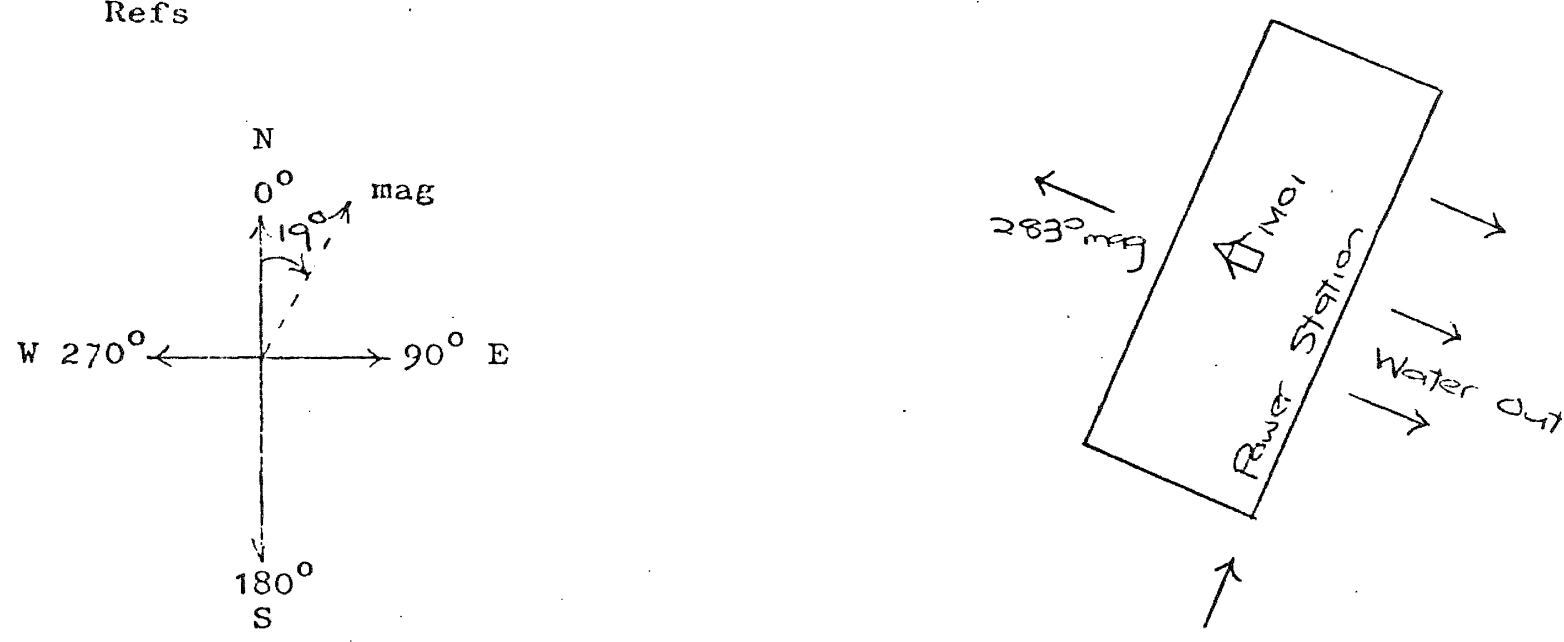

$130 \mathrm{mag}$

Figure: 2 Accelerograph Orientation sheet 
DEPARTMENT OF SCIENTIFIC AND INDUSTRIAL RESEARCH

[

PEL

Reference: $121 / 7 / 8$
PHYSICS AND

ENGINEERING

LABORATORY

Piivate Bag.

Lower Hutt, New Zealand.

Telephone: $6669 i 9$

Cables and tele'giams: PHYSICAL

Telex: PHIYSICSN.Z. 3814

18 January 1983

Principal Keeper

Castlepoint Likhthouse

Private Bag 183

MASTERTON

Dear Sir,

Officers from this laboratory will be in your area later

this month to scrvice earthquake recorders.

They will visit the instrument in your buildinc between

7 th -15 th February 1983.

Yours faithfuldy Puxpt Fratel

(Pamela :I.Randal)

for Director

Figurc: 3 Notification of Field Service Visit. 

MAINTENANCE

\begin{tabular}{|c|c|c|c|}
\hline M.O. 2A & Martinborough & Replace batteries & 1 \\
\hline $\begin{array}{l}\text { S.P. } 2 \\
\text { M.O. } 1\end{array}$ & Masterton & & 1 \\
\hline S.P. 2 & Castlepoint & Check stylus & \\
\hline S.P. 2 & Pahiatua & & \\
\hline $\begin{array}{l}\text { S.P. } 2 \\
\text { M.0.1 }\end{array}$ & Dannevirke & $\begin{array}{l}\text { Replace batteries } \\
\text { Time M.O. } 1\end{array}$ & 1 \\
\hline M.0.1 & Waipawa & Copy of record & 1 \\
\hline $\begin{array}{l}\text { S.P.2 } \\
\text { M.O.1 }\end{array}$ & Napier & $\begin{array}{l}\text { Replace batteries } \\
\text { Time M.O.1 }\end{array}$ & 1 \\
\hline M.0.1 & Wairoa & & 1 \\
\hline $\begin{array}{l}\text { S.P. } 2 \\
\text { M.O.2A }\end{array}$ & Tuai & Replace batteries & 1 \\
\hline $\begin{array}{l}\text { S.P. } 2 \\
\text { M.O.2 }\end{array}$ & $\begin{array}{l}\text { Gisborne } \\
\text { Gisborne P.O. }\end{array}$ & $\begin{array}{l}\text { Replace batteries } \\
\text { Remote Site: Film slowing up. }\end{array}$ & 4 \\
\hline S.P. 2 & Tolaga Bay & & \\
\hline M.0.1 & $\begin{array}{l}\text { Te Araroa } \\
\text { School }\end{array}$ & $\begin{array}{l}\text { Replace batteries } \\
\text { Time M.0.1 }\end{array}$ & 1 \\
\hline S.P. 2 & Opotiki & & \\
\hline M.0.2A & Maraenui & Replace batteries & 1 \\
\hline $\begin{array}{l}\text { M. } 0.2 \\
\text { M. } 0.2 \mathrm{~A}\end{array}$ & Matahina & $\begin{array}{l}\text { Replace all batteries } \\
\text { Paint cover boxes }\end{array}$ & $\begin{array}{l}4 \\
1\end{array}$ \\
\hline S.P. 2 & Rotorua & Check orientation & \\
\hline S.P. 2 & Taupo Police & New S.P. Top & \\
\hline M.0.2 & Moawhango & Check site conditions & 3 \\
\hline M.0.1 & Turangi & Check oil in block & 1 \\
\hline
\end{tabular}




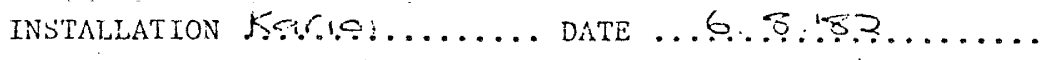
SITE NUMBER . 1.9.?........ INSTRUMENT MO..

\section{SECTION 1}

RECORD COUNTER READS $\ldots . . . ?$

TIME TO CORLLETE TEST RUN 1 4.3. OLD) BATTERIES (No load).1?.:.2.5...v (ON load)..1.1..75..v REWIND FILIY COUNTING TURNS $\ldots .15 \ldots . . . .$. (Approx $4 /$ run) REMOVE CASSETTE NUMBER .....7.3.9.

REMOVE SILICA GEL YES/WOr

\section{SECTION 2}

CHECK LIGIT SPOTS ON VIEWING CASSETTS

.8.:5

MOTOR CURKENT TESTS

(Tests done with special Cct Bd \& meter \& Trigger

Tester)

No film between 1 and $1.5 \mathrm{~mA} \ldots \ldots \ldots \ldots . . \ldots \ldots$ mA Slip Clutch between 10 and $18 \mathrm{~mA} \ldots \ldots .5 . \ldots \ldots \ldots \ldots \mathrm{mA}$ Trigger Test $\ldots \ldots \ldots \ldots \ldots \ldots \ldots \ldots \ldots \ldots \ldots \ldots \ldots \ldots \ldots \ldots \ldots \ldots \ldots \ldots$

\section{SECTION 3}

INSERT NEW BATTERIES

YES/ NA

INSERT CASSETTE NUMBER

6.

RERLACE NEW SILICA GEL BESIDE CASSETTE

TIME TO COMPLETE TEST RUN

YES/WO

CHECK SPOOL IS TURNING

YES/NO

COUNTER LEFT ON .....

sheat.

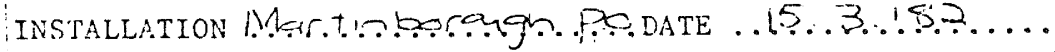

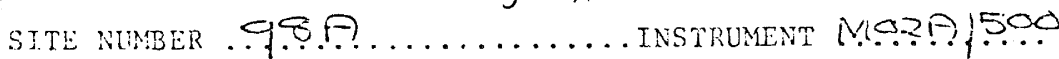
SECTION 1

COUNTER READS

FILM USED ... \begin{tabular}{|l|l|l|}
\hline 0 & 1 & 2 \\
\hline
\end{tabular} TEST RUN 1 TIHE: ...9...HRS.....9...MIN......9. SEC OLD EATTERIES (io ioad) $\ldots \ldots \ldots \ldots$ (ON load) $\ldots \ldots \ldots$. RENIND FILM COUNIING TURNS .... $6 \ldots \ldots \ldots \ldots \ldots \ldots$ Renove cassette number ...... . REMOVE STLICA GEL

Les/No Scribe details on film $\checkmark$

\section{SECTION 2}

CliECK LICHT SPOTS ON VIEWING CASSETTE $\ldots \ldots \ldots . \ldots \ldots \ldots$ CHFCK TIMING LAMP ALIGNMENT $\ldots \ldots \ldots \ldots \ldots \ldots . \ldots \ldots \ldots$ CHECK ELAPSEd TIME display $\ldots \ldots \ldots \ldots \ldots \ldots . \ldots \ldots \ldots$ MOTOR CURRENT TESTS: No film 8 - $10 \mathrm{~mA} \ldots \ldots \ldots \ldots \ldots$ mA (

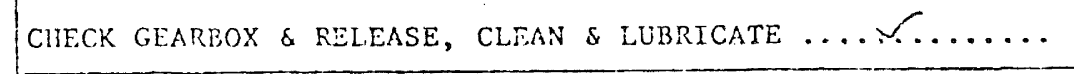
SECTION 3

INSERT NEW BATTERIES YES/RO

INSERT CASSETTE NUMBER . . . .6.7.

REPLACE NEW SILICA GEL BESTDE CASSETTE

YES / NO

RESET CLOCK NOTE TIME: ...9. . HRS .3.9. MIN ..... SEC 2 TEST RLNS TO USED EXPOSED FILM. CHECK SPOOL TURNING $\checkmark$ NOTE TIME FOR END RUN 2 .9..HRS, HC NIN ...!... SEC

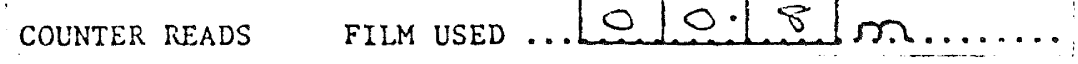

Figure: 6 M.0.2A Field Test sheet. 
books. Staff carry a separate master key to open the padlocks on instrument cover boxes, and a spare master key and padlocks are carried in the field tool kit as well.

While one technician services the accelerograph the assistant reads out the check list (Figs. 5 and 6 ) contained in each field book and notes details. Film cassettes are changed every visit with a test run performed to check the operation of the instrument before removing the old film. Failure of the instrument to trigger indicates that the accelerograph would not have triggered for an earthquake and the instrument is regarded as having been out of operation for the previous 8 months. The batteries are replaced if scheduled, or else their voltage is checked. Checks of the interconnection system are performed for multiple instrument installations.

Accurate documentation of the number of the film cassette removed is important because many sites are serviced and this is the only way to ensure correct identification of any earthquake records obtained. Site identification is scratched on the end of each film so it can be identified when removed from the cassette for processing. At the completion of each day a summary of the work carried out is prepared together with any expenditure incurred and other relevant details.

\section{Documentation and Film Processing:}

On return to the laboratory all the information from the field books is written up in a master laboratory copy. This is a back up system in the event a field book should be lost or destroyed. The scratch plate slides retrieved are viewed using a converted micro-film viewer, and any slides showing a peak acceleration exceeding $0.05 \mathrm{~g}$ are photographed using a specially adapted $35 \mathrm{~mm}$ camera, to give a 10 times enlargement.

All films retrieved from field instruments are carefully processed in the Laboratory by the field staff. The full length of film from any accelerograph that contains an earthquake record or suspected record is wound onto a "Nikor" stainless steel spiral in the darkroom and developed in total darkness using Kodak D19 developer, then fixed, spray washed and dried while still on the spiral. This reduces unnecessary handling of the film, while it is wet. Films from accelerographs that have not been triggered are then processed to enable staff to examine the quality of the traces written on the film during test runs. After eight months in damp, wet or hot conditions some deterioration of the film may be observed. After the films are dried they are examined over a light box and any films containing records are identified using a computer compatible identification system. The peak horizontal accelerations are roughly read off the film using a magnifying glass with $0.5 \mathrm{~mm}$ graticules. These accelerations together with the supporting calculations and computer identifier are listed so that scientific staff can decide if further computer processing (2) is warranted. Normally film records with an acceleration greater than $0.05 \mathrm{~g}$ are copied immediately using a PEL designed and manufactured direct copying system.

This also imprints on the copies accurate reference points for the laboratory digitizing system based on the LSI-II mini-computer which is linked to the DSIR Computer network. Original scratch plate records and MO records are then individually sealed into moisture proof containers and placed in the PEL fire-proof vault. Handling of original earthquake records is kept to a minimum, and any analyses of earthquake records are carried out on copies only. A representative sample of the processed film from each accelerograph is kept for comparison with film samples from previous field visits. Any long term deterioration in accelerograph performance can be observed. After the film processing has been completed a summary of the work done on that field visit is compiled. Any defects in accelerograph operation observed during examination of the film samples are noted on the work schedule sheets to enable remedial action on the next service visit to that zone. If an accelerograph or accelerometer block has been installed, removed or replaced the computer site file is updated.

A graph is kept in the Laboratory of the total number of accelerographs installed and the number that are nonoperational. Any accelerograph that does not trigger for a test run after being in the field for its eight month period, does not produce readable film traces or has not transported the film correctly during the test runs is regarded as non-operational, and this is noted on the graph. The percentage of faulty accelerographs is an indication of the quality of field servicing and if the percentage of faulty accelerographs increases from the normal of $5 \%$ per year non-operational, the cause in the decline in accelerograph reliability is investigated. This is normally caused by one accelerograph or an interconnected set of accelerographs and additional effort is concentrated on this site to overcome the problem. This is usually remedied by shifting the accelerographs to a less hostile environment, replacing the accelerographs or making different mounting details.

Computer-processed digitized accelerograms of twenty of the larger three-component records have been published (2), and work is progressing on digitizing the larger events each year for publication in the same form. This processing supercedes the earlier procedure of publishing accelerograms as enlarged prints of the film records(3). Computer tapes of the digitized records are available from PEL at a nominal charge. Film prints of any record can be provided to interested users.

Laboratory Support for Operating a Strong-Motion Network:

As indicated so far, there is much 
more involved in operating a strong-motion accelerograph network than buying a few instruments and placing them in the field. As earthquakes are rare events, and when a major event occurs it is important that all instruments in the region record it, it is vital that any agency running a strong-motion network has sufficient instruments spread over a wide enough area for a number of events to be recorded every year to produce confidence in the servicing procedures. Considerable auxiliary equipment is required to operate the instruments and process the records: accelerometer calibration and field test equipment, film processing and copying facilities, digitizing equipment and adequate instrument spares. PEL is fortunate in having both within engineering seismology and other fields such as optics, electronics and mechanical engineering the technical and scientific expertise and facilities to maintain the network, upgrade the accelerographs, develop and implement the accelerogram processing techniques, and interpret the records. The broad range of facilities within the laboratory has allowed the accelerographs to be continually developed to improve their performance and incorporate new features as these become available or desirable.

\section{Latest Modifications to the MO Accelerograph:}

To enable studies to be done on microzone effects, differential motion, wave propagation and attenuation from a set of close spaced accelerometers, consideration is being given to utilizing a radio signal to synchronize the microzone recorder network located in Wellington and the Hutt Valley. The earthquake event would be detected by a $P$ wave trigger located at PEL and after a delay sufficient to ensure that all instruments in the microzone network have had the opportunity to trigger, say 10-15 seconds, a signal is transmitted from 2LFS, the laboratory frequency standard transmitter. This signal would be received simultaneously at each accelerograph site by small receivers which had switched on using the accelerograph $P$ wave trigger. The signal received would be used to interrupt the accelerograph time marking lamp for a short period which would allow all records obtained to be synchronized. As the radio receivers would only be in operation during the running of the accelerographs, the existing sets of dry cell batteries would have sufficient capacity to run this system. It is hoped a synchronization accuracy for earthquake records of 0.04 seconds can be achieved. This system would not cause false triggering of the accelerographs and in the event of a failure of the radio receiver or transmitter the accelerographs would operate in the normal way.

A programme is also underway to recondition the MO2 accelerographs in the field which have now been in service for up to 16 years. The electronics in these accelerographs have become obsolete and the film drive motors are now unavailable. The completely upgraded model is designated type MO2A and a description of its features has already been given (4). As the accelerographs are reconditioned, all circuit boards, motors etc., become available as spares to enable existing MO2's to continue in service.

\section{Digital Instruments:}

A 6 channel digital recorder that has been developed by a New Zealand manufacturer, Solid State Equipment Ltd, is under evaluation by the Laboratory as a future replacement of the mechanical optical accelerographs. This type of recorder would allow recorded earthquakes to be computer processed directly from magnetic tape and be available for analysis more quickly than film records that need a lengthy digitising process. Three of these recorders are in operation at present. Two are installed in a government office building in Wanganui, and are maintained under contract to Ministry of Works and Development by the manufacturers, and one recorder, which has been funded by the National Roads Board, is installed beside an $\mathrm{MO} 2$ in the Bowen street overbridge in Wellington and is maintained by PEL to gain operating experience and to check its performance and accuracy against the MO2 accelerograph.

\section{William Clayton Building:}

The William Clayton Building (5) located in Molesworth Street, Wellington, is the first base isolated building in the world to use a lead rubber baseisolation system. For the last two years while building construction has been progressing, a smoked plate movement device has been fixed to the foundation system above and below the rubber base isolation to record building movement. Further displacement monitors are being installed at present. Since the completion of the building in July 1982, the laboratory has installed four interconnected MO2A accelerographs (fig. 7). One accelerograph is located in the centre of the building on the foundation grid. Two MO2A's are located immediately above the rubber bearings at opposite corners of the building and one MO2A is located on the building structure in the centre at roof level. An additional Mo2A will be installed on the ground, at a site yet to be selected, remote from the building.

\section{South Rangitikei Railway Bridge:}

The South Rangitikei Railway bridge (6) completed in 1981, which utilizes a stepping-pier concept with steel twisting-beam energy absorbers to provide base-isolation from earthquakes, has been equipped with three MO2 strong-motion accelerographs. One MO2 was installed close to the site while the bridge was under construction and earthquake records with peak accelerations of $0.069 \mathrm{~g}$ (10 June 1975) and $0.052 \mathrm{~g}$ (24 June 1980) were obtained. The three MO2 accelerographs, which are interconnected to give common triggering and time marks, are located as follows (fig. 8): near the steel damper energy absorber on pier 4, in the deck above this pier and the third at a remote site 


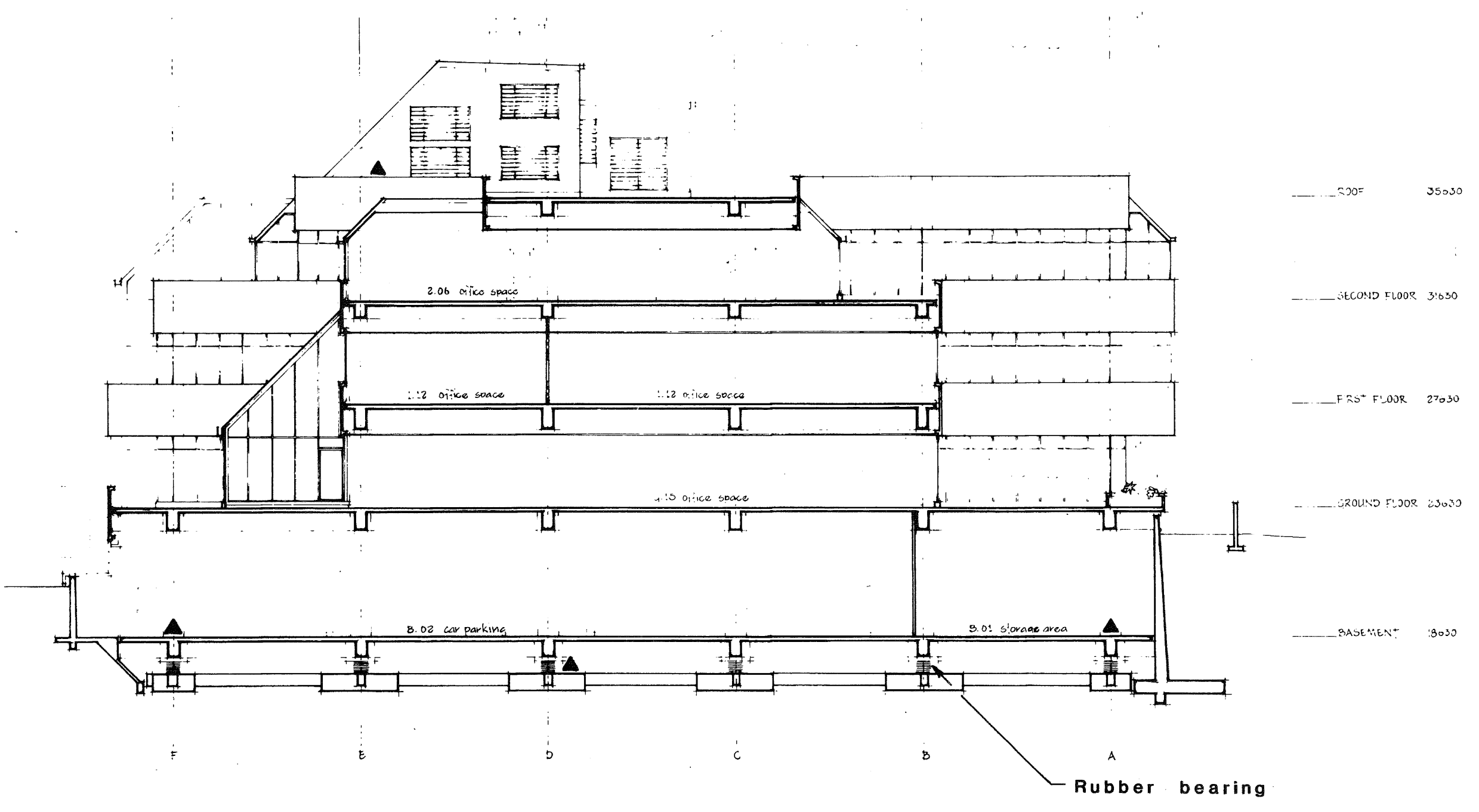

Figure: 7 WILLIAM CLAYTON BUILDING

Key : MO2A Accelerograph 

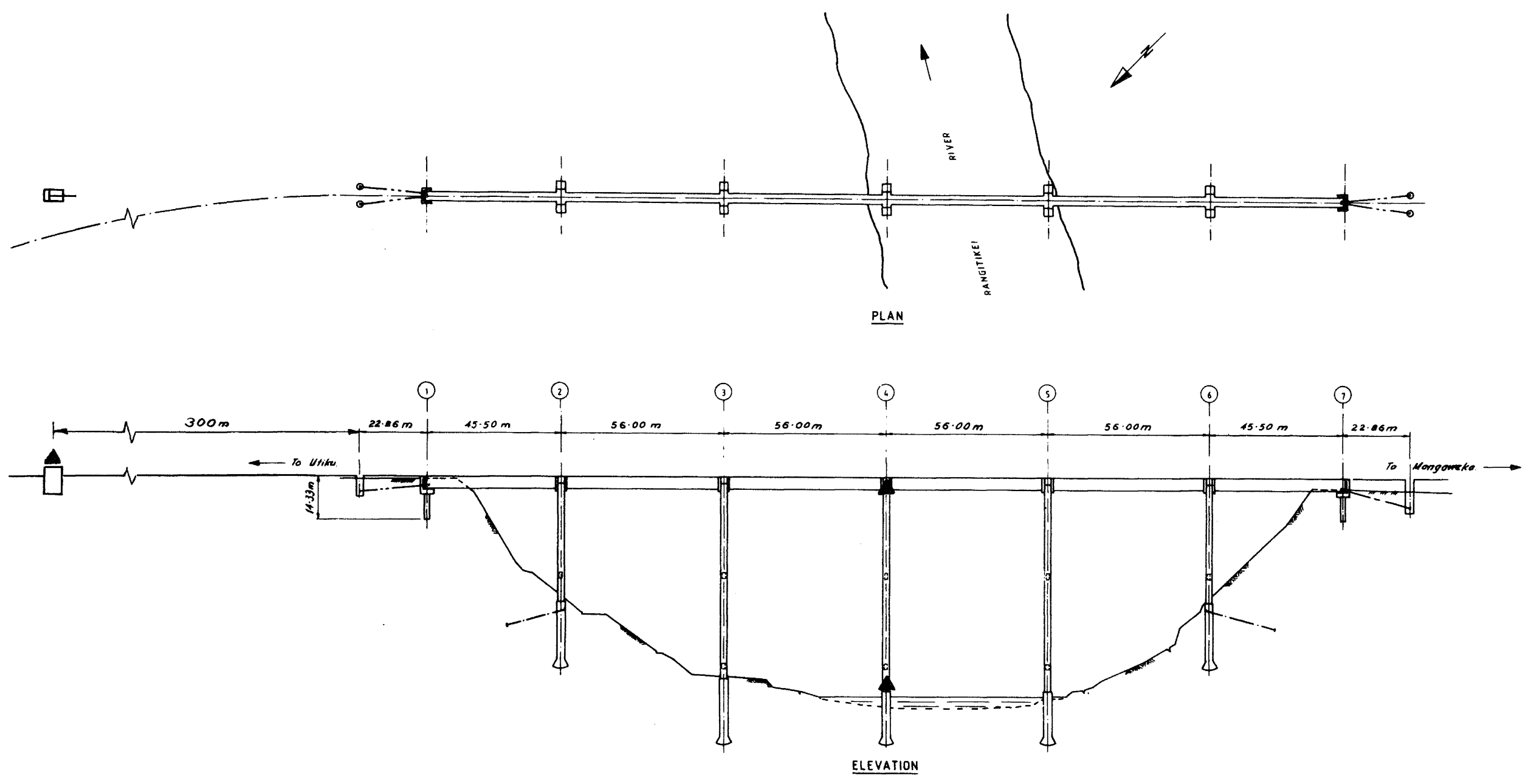

Figure : 8 SOUTH RANGITIKEI BRIDGE

Key : $\triangle$ MO2 Accelerograph 
on the anchor block that had been used for the "flying fox" during bridge construction. The anchor block is located approximately $300 \mathrm{~m}$ from the bridge structure and is a large concrete block founded on papa bedrock.

A prototype mechanical movement recorder has been designed and constructed by the Instrument Development Section of PEL and is to be installed beside the steel dampers at the bottom of pier 4 to record uplift of the pier leg during earthquake attack. This recorder uses the movement of the pier leg to advance the recording paper as well as writing the record, so that the number of cycles and the distance the pier leg has moved can be recorded. Field trials will be conducted to prove the operation and if this device is successful most of the piers on the bridge will be fitted with these recorders.

\section{Conclusions:}

The DSIR strong-motion recorder network has been set up to record the accelerations of the infrequent large earthquakes that damage property in New Zealand. Presently the "design earthquakes" used in New Zealand are based primarily on United States records, and it is vital for the next major event in this country to be recorded in the epicentral region. The many small earthquakes which have occurred since the deployment of the network have provided field tests of the equipment and servicing procedures, and with an eight month servicing interval $95 \%$ of the instruments have been found operational on the next visit, which ranks with the best reliability which has been achieved overseas, often with much shorter periods between servicing. However, even now the recording of strong shaking from earthquakes in many regions in the country is reliant on a single three-component recorder and the present policy of replacing obsolescent scratch-plate instruments by three-component time based instruments will be pursued as funds become available. The lack of structural instrumentation in the two to threestorey commercial buildings which are typical of many New zealand towns must be remedied.

\section{Acknowledgements:}

The authors would like to thank Dr G.H. McVerry, Dr S.B. Hodder and Dr R.G. Tyler for their useful discussions and suggestions during preparation of this manuscript.

\section{References:}

1. Hefford, R.T., Randal, P.M. et al. "The New Zealand Strong-Motion Earthquake Recorder Network", Bull. of the NZ National Society for Earthquake Engineering, Vol. 12 No. 3, September 1979.

2. Beck, James L., Randal, Pamela M. and Hefford, Richard T., "Computer Analyses of New Zealand Earthquake Accelerograms", Vol. 1, Physics and
Engineering Laboratory, DSIR, Lower Hutt, 1981.

3. Skinner R.I., Hefford R.T., Randal P.M. et al. "Strong Motion Earthquake Records in New Zealand" "Physics and Engineering Laboratory, DSIR, Vol. 1 (1965-1970), Vol. 2 (1971), and Vol. 3 (1972)

4. Hefford, R.T., Tyler, R.G., and Skinner, R.I., "The MO2A Strong-Motion Accelerograph". Bull. of the NZ National Society for Earthquake Engineering, Vol. 13, No. 4, December 1980 .

5. Megget, L.M., "Analysis and Design of a Base-Isolated Reinforced Concrete Frame Building". Bull. of the NZ National Society for Earthquake Engineering, Vol. 11, No. 4, December 1978.

6. Tillay, Clive. "South Rangitikei Railway Bridge Construction: . NZIE Transactions. Vol. $82 / \mathrm{CE}$. July 1981 